\title{
A Study on Role of Big 5 Personality Traits on Social Ostracism
}

\author{
P. Manoj Kiran \\ Anna University, Chennai, Tamil Nadu, India
}

\section{OPEN ACCESS}

Manuscript ID:

MGT-2020-08023430

Volume: 8

Issue: 2

Month: October

Year: 2020

P-ISSN: 2321-4643

E-ISSN: 2581-9402

Received: 13.08.2020

Accepted: 20.09.2020

Published: 01.10.2020

Citation:

Manoj Kiran, P., and A. Thiruchelvi. "A Study on Role of Big 5 Personality Traits on Social Ostracism." Shanlax International Joural of Management, vol. 8, no. 2, 2020, pp. 103-107.

DOI:

https://doi.org/10.34293/

management.v8i2.3430

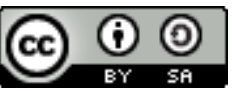

This work is licensed under a Creative Commons Attribution-ShareAlike 4.0 International License.

\author{
A.Thiruchelvi \\ Associate Professor, Department of MBA, Anna University, Chennai, Tamil Nadu, India \\ https://orcid.org/0000-0002-3453-1884
}

\section{Abstract}

Social Ostracism is an act of isolation of individuals. This feeling of isolation induces feelings of negative emotions on humans. It causes anger, depression, and loneliness among people left out or deprived of social interaction. So it's important to study the causes of Social Ostracism and its implications on life satisfaction. This study assesses the role of the Big five personality traits on Social Ostracism and the relationship between Social ostracism and life satisfaction. This study uses a convenient sampling of data of 113 individuals, both male and female. The study finds that there exists a significant relationship between personality traits and Social ostracism. Also, there exists a relation between personality traits and life satisfaction. Social Ostracism hurts life satisfaction.

Keywords: Extraversion, Agreeableness, Neuroticism, Conscientiousness, Openness, Big Five Personality Traits, Social Ostracism and Life Satisfaction

\section{Introduction}

Social ostracism influences the way people treat others and others to treat them (Williams, 1997, 2001, 2007). Being socially ostracised creates all bad emotions on human beings that encourage them to do things that are not welcomed by society. According to Andy Hales, a postdoctoral researcher in social psychology from the University of Virginia, human motivation is needed for people to live a meaningful existence because people want constant validation from others; when they are deprived of it, they do indulge in bad things. When they want to show their meaningful existence, they tend to do things by aggression and cause harm to themselves and others.

\section{Big 5 Personality Traits and Social Ostracism}

In the early 1990s, researchers such as (Digman 1990) (Goldberg, 1990) and (McCrae and Costa, 1992) worked on the Five-Factor Model (FFM) of personality traits that describe individual personality differences at an abstract level. According to (Digman 1990), the five-dimensional personality structure model consists of extraversion, agreeableness, conscientiousness, emotional stability, and autonomy. Extraversion includes a variety of factors, such as how social or outgoing a person is. As (Watson and Clark, 1997) point out, "extroverts are more sociable, but they are also described as more active and impulsive." (Tokar et al., 1998) report results that relate extraversion positively to job performance. Agreeableness shows facets such as trust and simplicity, which means being forgiving. "Agreeableness seems lukewarm for a dimension that seems to involve the most human aspects of humanity, such as altruism, nurture, care, and emotional support." However, (Nyhus and Pons, 2005) see that "agreeableness has an ambiguous effect on earnings." 
They argue that it may have incentive improvement characteristics, since employers may want to reward nice people who react positively to employers' incentives. Conscientiousness means, among other properties, that people are efficient, organized, careless, and not lazy. Conscientiousness is a consistently valid predictor that estimates one's job performance for all occupational groups, as well as the (Barrick and Mount, 1991). Conscientiousness is a good predictor of work performance (Heineck, 2011). Neuroticism describes being tense, anxious, in a bad mood, or not sure of himself.

\section{Social Ostracism and Life Satisfaction}

Social ostracism is a form of isolation. It makes people feel alone. It can happen for friends, family, relatives, and colleagues in the workplace. Ostracism extends to many places, such as in all social gatherings and places like schools, colleges, religious gatherings, and functions (Williams, 1997). Social ostracism is bad for individuals. It has been shown that ostracism has a negative influence on individuals and causes them bad experiences (Chow, 2005). There is a constant need for humans to mingle with groups and find a meaningful life (Eisenberger, 2005). Mostly adolescents develop this social ostracism (Witvliet, 2010). Other studies show that social ostracism can lead to all kinds of mood swings and disorders (Leary, 2003) and uncontrollable emotions (Sebastian, 2010). Since ostracism creates all possible negative emotions on humans, they tend to do all bad things to the society in the back (Williams, 2009). Social ostracism levels depend on how individuals can tackle social anxiety in them (Zadro, Boland, and Richardson, 2006).

\section{Life Satisfaction and Well Being}

Satisfaction with life is a state experienced by a person subjectively (Shin and Johnson, 1978). It is an evaluation based on subjective experience rather than objectivity; it differs from person to person. Since satisfaction with life is not measured by objective terms such as money, status, relationship, and work. It is a measure of how an individual feels about his life. Satisfaction with life can be defined by individuals rather than other people's points of view (Diener ED, 1985). Satisfaction with life is a component of a broader concept, subjective wellbeing. The construction of subjective well-being has two components, emotional component, and cognitive component. Well, being of a person is linked to positive emotions such as happiness levels and joy (Pavot, 2009). Positive emotions create a sense of satisfaction in all the people who experience it; they feel satisfied financially, physically, mentally, and all other aspects (Kimm H, 2012).

\section{Hypotheses}

Hypothesis 1: Big five personality traits have a Positive Impact on Social Ostracism.

Hypothesis 2: Social Ostracism has a negative impact on Life Satisfaction.

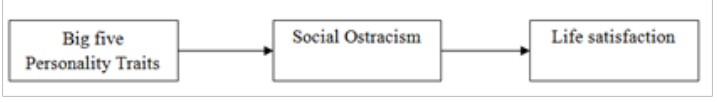

Figure 1: Proposed Model

\section{Methods \\ Samples and procedures}

Respondents were selected randomly at Chennai, Tamilnadu. Google forms were sent to them individually by assuring the confidentiality of the data. "Of the 113 respondents, $49.6 \%$ were male, $50.4 \%$ were female. $54.9 \%, 31 \%, 14.2 \%$ were from Urban, semi-urban, and rural respectively".

\section{Measures}

\section{Big five personality traits}

The scales in the questionnaire are ranged from 1, "strongly disagree" to 5, "strongly agree." A forty-four scale developed by Goldberg (1993) was used to measure "the Big-Five personality traits of employees: extraversion, Agreeableness, neuroticism, Conscientiousness, and openness to experience." "Cronbach alpha coefficient is almost $0.8 ”$.

\section{Social Ostracism}

"Social ostracism is measured by a 19 item scale". Mostly all questions are generalized and do not denote a particular community or people (a particular friend, romantic partner, relative, etc.). The Cronbach alpha coefficient is almost 0.8 " (Rich Gilman, 2012). 


\section{Life satisfaction}

Life satisfaction is measured by using a 5 item scale. "Participants indicate how much they agree or disagree with each of the five elements using a 7 -point scale that varies from 7 totally according to 1 disagree". Cronbach's average alpha coefficient was found to be 0.8 .

\section{Regression Analysis}

All the proposed hypotheses are tested using regression analysis, and the results are tabulated and interpreted in this section.

Hypothesis 1: Big five personality traits have a positive impact on Social Ostracism.

Table 1: Big Five Personality Traits Versus Social Ostracism

\begin{tabular}{|l|c|c|c|c|c|}
\hline \multicolumn{1}{|c|}{ Variables } & Standard Beta & Sig & t-value & Tolerance & VIF \\
\hline Agreeableness & -0.346 & $0.000^{* *}$ & -3.668 & .743 & 1.346 \\
\hline Conscientiousness & -0.034 & 0.723 & -0.355 & .709 & 1.411 \\
\hline Extraversion & -0.235 & $0.007^{* *}$ & -2.748 & .905 & 1.105 \\
\hline Openness & -0.039 & 0.646 & -0.461 & .948 & 1.055 \\
\hline Neuroticism & 0.158 & 0.073 & 1.811 & .866 & 1.155 \\
\hline $\mathrm{R}^{2}$ & .291 & & & & \\
\hline Adjusted R ${ }^{2}$ & .258 & & & & \\
\hline Durbin-Watson & 1.986 & & & & \\
\hline F & 8.794 & $.000^{\mathrm{b}}$ & & & \\
\hline Dependent variable: Social Ostracism \\
$* *$ p is significant at the 0.01 level
\end{tabular}

In support of hypothesis 1 , table 1 indicated that independent variables Agreeableness, Conscientiousness, Extraversion, Openness, Neuroticism explaining $29.1 \%$ variance in dependent variable Social ostracism and $(\mathrm{p}<.05)$, which is statistically significant in Table 1 and from table $1(\beta=-.346, \mathrm{p} \leq .01)$ indicates "Agreeableness is negatively related to Social ostracism." ( $\beta=-.034$, $\mathrm{p} \geq .01$ ) indicate "Conscientiousness is negatively related to social ostracism." $(\beta=-.235, \quad \mathrm{p} \leq .01)$ indicate "Extraversion is negatively related to Social ostracism." $(\beta=-.039, \mathrm{p} \geq .01)$ indicate "Openness is negatively related to Social ostracism" and $(\beta=.158$, $\mathrm{p} \geq .01$ ) indicate "Neuroticism is positively related to Social ostracism."

Hypothesis 2: Social Ostracism hurts Life satisfaction

Table 2: Social Ostracism versus Life Satisfaction Variables

\begin{tabular}{|c|c|c|c|c|c|}
\hline Variables & Standard Beta & Sig & t-value & Tolerance & VIF \\
\hline Social Ostracism & $-.312 * *$ & .001 & -3.464 & 1.000 & 1.000 \\
\hline $\mathrm{R}^{2}$ & .098 & & & & \\
\hline Adjusted $\mathrm{R}^{2}$ & .089 & & & & \\
\hline Durbin-Watson & 2.151 & & & & \\
\hline $\mathrm{F}$ & 11.996 & $.001^{\mathrm{b}}$ & & & \\
\hline \multicolumn{6}{|c|}{ Dependent Variable: Life Satisfaction } \\
\hline
\end{tabular}

In support of hypothesis 2 , the independent variable Social ostracism explained $8.9 \%$ variance in the dependent variable Life satisfaction and $(\mathrm{p} \leq .01)$, which is statistically significant in Table 2 . From table $2,(\beta=-.312, p \leq .01)$ indicate Social ostracism is negatively related to Life satisfaction.

\section{Discussion}

This study found that Neuroticism positive correlate to life satisfaction and Extraversion and agreeableness is negatively correlates to social ostracism. Moreover, "Social ostracism is found to be negatively related to Life satisfaction." 
Life satisfaction is necessary for the well being of individuals. Thus this study finds that Social ostracism is caused by the personality traits of individuals, and it also hurts Life satisfaction.

\section{Practical Implications}

These study findings have significant applications to society. Satisfaction is one of the important factors that everyone strives for, be it in work or educational institutions. Every work we do is a constant need for validation and satisfaction. Given the importance of satisfaction with life, this study shows that social ostracism can be detrimental to life satisfaction. Social ostracism is caused by the personality traits of individuals. Importance should be given to improving the qualities of personality traits that children possess and improving their social skills to avoid ostracism that reduces the satisfaction and well-being of life.

\section{Strengths and Limitations}

This study uses data from trusted sources; a questionnaire was sent to them personally through Google forms. Since we have used a 44 item big five personality questionnaire by (Goldberg 1993), predicts the personality more accurately. This study also corroborates with the previous study (Longzeng $\mathrm{Wu}, 2011$ ), extraversion, agreeableness, and neuroticism have an impact on ostracism on individuals in the workplace. The limitations are, we have used only 113 respondents for many questions used in this research, and there are various other factors that are important to study on the dispositions of social ostracism; many situational factors also play an important role in social ostracism which can be studied further in future research.

\section{Conclusion}

Despite these limitations, the present study has dealt with some of the important problems regarding the background and impact of social ostracism. This study revealed that "individuals with low levels of extraversion, agreeableness and emotional stability are more likely to be excluded, and that social ostracism negatively influenced satisfaction with life." This study will make way for future research to advance the research in the understanding of the other factors that influence social ostracism and its serious consequences on society.

\section{References}

Barrick, Murray R., and Michael K. Mount. "The Big Five Personality Dimensions and Job Performance: A Meta-Analysis." Personnel Psychology, vol. 44, no. 1, 1991, pp. 1-26.

Baumeister, Roy F., and Mark R. Leary. "The Need to Belong: Desire for Interpersonal Attachments as a Fundamental Human Motivation." Psychological Bulletin, vol. 117, no. 3, 1995, pp. 497-529.

Chow, Henry P. H. "Life Satisfaction among University Students in a Canadian Prairie City: A Multivariate Analysis." Social Indicators Research, vol. 70, 2005, pp. 139-150.

Costa, Paul T., and Robert R. McCrae. "Normal Personality Assessment in Clinical Practice: The NEO Personality Inventory." Psychological Assessment, vol. 4, no. 1, 1992, pp. 5-13.

Diener, Ed., et al. "The Satisfaction With Life Scale." Journal of Personality Assessment, vol. 49, no. 1, 1985, pp. 71-75.

Digman, J.M. "Personality Structure: Emergence of the Five-Factor Model." Annual Review of Psychology, vol. 41, 1990, pp. 417-440.

Eisenberger, Robert, et al. "Flow Experiences at Work: for High Need Achievers Alone?" Journal of Organizational Behavior, vol. 26, no. 7, 2005, pp. 755-775.

Robinson, Eric, et al. "Eating Attentively: A Systematic Review and Meta-Analysis of the Effect of Food Intake Memory and Awareness on Eating." The American Journal of Clinical Nutrition, vol. 97, no. 4, 2013, pp. 728-742.

Fayard, Jennifer V., et al. "Uncovering the Affective Core of Conscientiousness: The Role of SelfConscious Emotions." Journal of Personality, vol. 80, no. 1, 2012, pp. 1-32.

Gilman, Rich, et al. "Validation of the Ostracism Experience Scale for Adolescents." Psychological Assessment, vol. 25, no. 2, 2012, pp. 319-330.

Goldberg, L.R. "An Alternative "Description of Personality": The Big-Five factor structure." 
Journal of Personality and Social Psychology, vol. 59, no. 6, 1990, pp. 1216-1229.

Gröpel, Peter, and Piers Steel. "A Mega-Trial Investigation of Goal Setting, Interest Enhancement, and Energy on Procrastination." Personality and Individual Differences, vol. 45, no. 5, 2008, pp. 406-411.

Heineck, Guido. "Does it Pay to Be Nice? Personality and Earnings in the United Kingdom." ILR Review, vol. 64, no. 5, 2011, pp. 1020-1038.

Kimm, Heejin, et al. "Life Satisfaction and Mortality in Elderly People: The Kangwha Cohort Study." BMC Public Health, vol. 12, 2012.

Klein, Daniel N., et al. "Personality and Depression: Explanatory Models and Review of the Evidence." Annual Review of Clinical Psychology, vol. 7, 2011, pp. 269-295.

Leary, Mark R., et al. "Teasing, Rejection, and Violence: Case Studies of the School Shootings." Aggressive Behavior, vol. 29, no. 3, 2003, pp. 202-214.

Zadro, Lisa, et al. "How Long Does it Last? The Persistence of the Effects of Ostracism in the Socially Anxious." Journal of Experimental Social Psychology, vol. 42, no. 5, 2006, pp. 692-697.

Nyhus, Ellen K., and Empar Pons. "The Effects of Personality on Earnings." Journal of Economic Psychology, vol. 26, no. 3, 2005, pp. 363-384.

Pavot, William, and Ed Diener. "Review of the Satisfaction with Life Scale." Assessing wellbeing: The Collected Works of Ed Diener, edited by Ed Diener, Springer, pp. 101-117.

Schimmack, Ulrich, et al. "Personality and Life Satisfaction: A Facet-Level Analysis." Personality and Social Psychology Bulletin, vol. 30, no. 8, 2004, pp. 1062-1075.

Sebastian, Catherine, et al. "Social Brain Development and the Affective Consequences of Ostracism in Adolescence." Brain and Cognition, vol. 72, no. 1, 2010, pp. 134-145.

Seligman, Martin. Flourish: A New Understanding of Happiness and Well-being and How to Achieve them, Nicholas Brealey Publishing, 2011.

Shin, D.C., and D. M. Johnson. "Avowed Happiness as an Overall Assessment of the Quality of Life." Social Indicators Research, vol. 5, 1978, pp. 475- 492.

Tokar, David M., et al. "Personality and Vocational Behavior: A Selective Review of the Literature, 1993-1997." Journal of Vocational Behavior, vol. 53, no. 2, 1998, pp. 115-153.

Watson, Dane, and Lee Anna Clark. "Extraversion and its Positive Emotional Core." Handbook of Personality Psychology, edited by Hogan, Robert, et al., Academic Press, 1997, pp. 767-793.

Williams, Kipling D. "Social Ostracism." Aversive Interpersonal Behaviors, edited by Robin M. Kowalski, Springer, 1997, pp. 133-170.

Williams, Kipling D., and Lisa Zadro. "Ostracism: On Being Ignored, Excluded, and Rejected." Interpersonal Rejection, edited by Mark R. Leary, Oxford University Press, 2006, pp. 21-53.

Williams, Kipling D. "Ostracism: The Kiss of Social Death." Social and Personality Psychology Compass, vol. 1, no. 1, 2007, pp. 236-247.

Witvliet, Miranda, et al. "Peer Group Affiliation of Children: The Role of Perceived Popularity, Likeability, and Behavioral Similarity in Bullying." Social Development, vol. 19, no. 2, 2010, pp. 285-303.

$\mathrm{Wu}$, Longzeng, et al. "Dispositional Antecedents and Consequences of Workplace Ostracism: An Empirical Examination." Frontiers of Business Research in China, vol. 5, 2011, pp. 23-44.

\section{Author Details}

P. Manoj Kiran, Anna University, Chennai, Tamil Nadu, India, Email ID: ugamanoj@gmail.com

A. Thiruchelvi, Associate Professor, Department of MBA, Anna University, Chennai, Tamil Nadu, India,

Email ID: thiruchelvi.y@gmail.com 